\title{
Music Studies, American Studies, and the Popular History of the Normal
}

\section{Barry Shank}
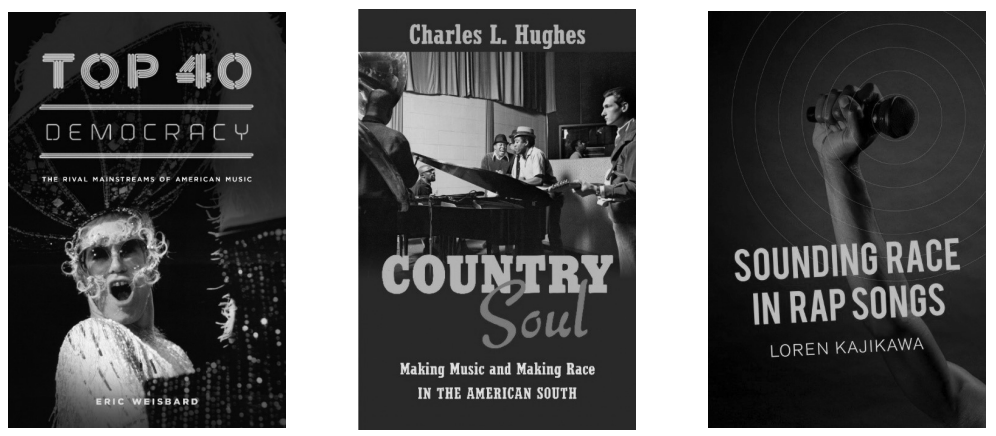

TOP 40 DEMOCRACY: The Rival Mainstreams of American Music. By Eric Weisbard. Chicago, IL: University of Chicago Press. 2014.

COUNTRY SOUL: Making Music and Making Race in the American South. By Charles L. Hughes. Chapel Hill: University of North Carolina Press. 2015. SOUNDING RACE IN RAP SONGS. By Loren Kajikawa. Berkeley: University of California Press. 2015.

The maturation of a scholarly field is marked not only by the development of its own infrastructure-scholarly associations, tenure-track appointments, book series with major presses, journals, and the like-but perhaps even more so by the revision of its earlier findings, a rethinking of outdated assumptions and judgments. Once a field has demonstrated its capacity to reconsider its 


\section{Barry Shank}

inherited truths, it has then reached the stage where it can also make significant contributions to other fields. These three books each revisit long-held shibboleths in popular music studies, identifying new historical continuities as they overturn some of the founding positions in the field. In so doing, these books also contribute to ongoing conversations about American studies. In particular, the version of popular music studies presented in all three of these books suggests that scholars of American studies could profit from returning our gaze to a popular history of the mundane. Together, they draw on new archives and new analytical concepts that support a refocus on the common, that recognizes the complexity and contingency of the normal.

Loren Kajikawa's insistence on the musicological value of the breakbeat as the core compositional unit of rap music reflects the means whereby rap producers create songs and, therefore, anchors the political analysis of rap's musical beauty in the actual everyday practices of the musicians. Particular breakbeats at the core of key soundtexts signal the relationships among signifiers of race within shifting political and economic contexts. With our attention fully focused on those intricate interrelationships, we can then hear the changing same of rap music as a full participant in the nation's turn to neoliberalism even while the form maintained a kernel of resistance. Charles Hughes invites us to consider the studio musicians, record producers, and label chiefs who recorded much of the great country and soul music of the late 1960s and 1970s as workers. Relationships in the workplace, where some musicians received producing or song-writing credit and royalties while others were paid for a day's work and forgotten, reproduced the racialized hierarchies that integrated studio ensembles had been imagined to have overcome. The shared musicians and musical roots that created the core sounds of ideologically opposed genres of country and soul music did not work as equal partners so much as cagey interlocutors negotiating ongoing tensions. Eric Weisbard reexamines the work of such figures as the Isley Brothers, Dolly Parton, Elton John, and the Carpenters who, along with label executives and radio DJs, competed for listeners via the construction of multiple mainstreams. Conceptualizing these mainstreams as formats instead of genres, Weisbard helps us to hear a democracy of the everyday, a struggle over the reach of the normal. Overturning the long-standing emphasis within popular music studies on artists who pushed musical boundaries or overtly demanded political change, Weisbard focuses our attention on the muddled middle, where musicians and industry professionals created soundtracks for family barbecues, housework, and office politics. Weisbard calls these "formatted experiences" (57) and argues that by eschewing the assumptions that link genres and social identities, we can better understand how formats competing for audiences mapped the messiness of actually functioning democracy.

Sounding Race in Rap Songs provides a chronological, but more importantly musicological, mapping of the transformation of hip hop culture from street corner parties in the Bronx and Brooklyn to the very center of American culture. Individual chapters are organized around a key "soundtext," which is then con- 
textualized both musically and socially. As Kajikawa puts it in the introduction, one purpose of the book is "to explain how each song produces particular ideas about race and genre." His analyses "are about providing an understanding of the aesthetic grounds from which rap's projections of race emerge" (8-9). Kajikawa adds to the canon of rap scholarship, building on the foundational work of such scholars as Tricia Rose, Murray Forman, Mark Anthony Neal, Imani Perry, Cheryl Keyes, Mark Katz and Joe Schloss among others, through his tightly focused analysis of individual songs. ${ }^{1} \mathrm{He}$ insists that "the sound of a song can carry quite a bit of content with it" (2, emphasis original). Rap songs, especially the breakbeats out of which the songs are constructed, convey historically and geographically particular images of racial identities via coded associations. "At the 'micro level' where musicians produce and fans listen to rap songs, race becomes meaningful (and audible) when particular aesthetic approaches become associated with certain ideas about social reality" (10). These are not permanent or essentialist associations. Rather, they vary historically. To illustrate his point, Kajikawa shows us how "[i]n 1989 ... Public Enemy sounded black to those convinced that real blackness (i.e., hip hop authenticity) personifies defiance, rebelliousness, and political engagement" (10). Yet, by 1992, Dr. Dre's The Chronic provided sounds and images of the good life in the context of the neoliberal gentrification of Los Angeles.

In order to demonstrate the analytical value of his musicology, Kajikawa uses a graphic representation to illustrate the interweaving of samples into complex and compelling breakbeats. Through this technique, he is able to show us how rap producers conceptualize their compositions. His focus on the construction of breakbeats is put to brilliant effect in the chapter that focuses on how Public Enemy's Bomb Squad sounded "a radical black aesthetic" (51). Kajikawa contrasts his technique with an early demonstration of the musical complexity of Public Enemy's work in an important article by Rob Walser. ${ }^{2}$ In a virtuosic display of analytical listening, Walser transcribed the music captured on the samples that underlay "Fight the Power," breaking the whole down into parts created on the original recordings by voices, guitars, synthesizers, bass and drum kit. This was a major advance at the time, defeating the ridiculous yet then common charge that rap was not music. After rightly praising Walser for creating "one of the first musicological attempts to grapple with the political implications of rap's sonic aesthetics" (55), Kajikawa critiques Walser's careful disarticulation of the samples into separate melodic and rhythmic lines. Kajikawa argues that transcribing these sounds into standard musical notation deprives them of their ontological status as samples. In so doing, transcription removes the actual ideas used by rap composers from its analysis. You might ask, "so what?" Kajikawa's point is that samples, not saxophone lines or snare paradiddles, are the units of composition in rap songs because it is samples that carry the tradition of breaks and their historical meanings with them. It is through breakbeats and the samples out of which they are constructed, not melodies, that race is signified. The samples that were built into "Rebel Without a Pause" consist of a saxophone 


\section{0}

wail and a drum break. But it is the way that they are "tightly wound," repeating "relentlessly every measure," that creates the meaningful sound at the core of the track (76). Kajikawa highlights the "noisiness" of the breaks used by the Bomb Squad and, by quoting from reviews published when It Takes a Nation of Millions was first released, shows us how that noise registered in the minds of listeners as signifiers of radical blackness. Kajikawa's focus on samples as a unit of composition enables him to trace the line from "hip hop DJ to rap music production," maintaining cultural continuity while accounting for technological transformation. In his detailed and careful analysis of "Rebel Without a Pause," Kajikawa renders clear the process whereby Public Enemy "revolutionized the break as a concept that encompassed a wider world of sound types" and "brought a black radical sensibility to rap music" (77-78).

This is just one example of the illuminating analyses that Kajikawa performs throughout this book. Other chapters detail the move from hip hop's origins in the nearly endless rhyming-over-breakbeat street parties to song-form recordings via "Rapper's Delight;" Dr. Dre's move to recording new instrumental versions of the beats he wanted to sample in order to maintain even more control over the precise sounds that were looped together, creating an open sonic space for "the ruthless individualism of post-soul politics" (115) and black neoliberal entrepreneurship; and later isolating the somewhat plodding backbeat that Dre constructed for Eminem's "My Name Is" as a signifying "square" and "white" ground against which the MC's rapping skill could stand out as a racially particular yet respectful participation in rap's construction of identity. In each case, Kajikawa interweaves his analyses of these soundtexts with careful delineation of their conditions of production and the long trajectory of rap's political force. By centering the breakbeat as the key unit of rap musicology, Kajikawa creates an analytical method that not only reflects the operating methods of rap producers but also enables a more precise articulation between politics and musical beauty.

Charles Hughes revisits the history of music-making in "the country-soul triangle," the recording studios located in Muscle Shoals, Alabama, and Nashville and Memphis, Tennessee. These studios and the music produced in them during the 1960s and 1970s have been at the center of one of the most longstanding myths in popular music studies. Integrated bands produced many great hits in both country and soul music, seemingly reinforcing the progressive trajectory of the South and the positive results of racial integration. Hughes's revision of this story is not the first. Nelson George, Craig Werner, and Brian Ward among others have noted the tensions generated by white management directing the work of black musicians. ${ }^{3}$ But Hughes directly challenges the version most forcefully articulated by Peter Guralnick and echoed in many popular music histories since then. ${ }^{4}$ In this story, these racially-mixed bands pointed the way forward, providing a model of integration for the rest of the country to follow. Those of us who still hold out a belief that music can exert a particular social or political force must come to grips with the history that Hughes has uncovered. By viewing this period through the analytical lens of labor history, Hughes shows us that these musi- 
cians "were craftspeople, not conduits." They were trained musicians working in specific conditions, not models for a racially egalitarian society. Recording music that emerged from black musical traditions and that was designed to appeal to black audiences first and foremost did little to change the racialized hierarchies in the recording studio. Indeed, as he makes clear, "The racial partnership at the heart of the country-soul triangle was fundamentally unequal" (6). In the studios that focused on soul in the mid-sixties, musicians like Steve Cropper were given producer credit. Not until years later did Isaac Hayes receive the same recognition. In the studios that focused on country, it was simply more profitable for white musicians to borrow sounds from soul and disco in order to reach a mainstream pop and rock audience. Inside the industry, it was always easier for the white musicians to crossover and to capitalize from that move.

Hughes's nuanced revision is most clearly told in the chapter that focuses on Stax Records. After Al Bell took over the management of Stax, he hired committed black activists Johnny Baylor and Dino Woodward to management positions. In the standard story, one that focuses on the experience of white participants, this action led directly to white co-founder Estelle Axton's quitting the company and selling her stock. Guitarist Steve Cropper claimed that these new hires destroyed the interracial alliances that were at the heart of Stax's success. Baylor and Woodward "brainwashed" black women who worked at the company as secretaries and maids, and "corrupted the good vibes" that had enabled the company to produce its early hits. Hughes flips this script and, while acknowledging that Baylor and Woodward did make financial mistakes and were not always easy for anyone to get along with, suggests that the women working for Stax had been underpaid and reminds us that Stax had major commercial successes well into the 1970s. The Shaft soundtrack, the Wattstax concert, film, and soundtrack LP, and the hits of the Staple Singers, were produced during this era. As Hughes shows us, both Baylor and Woodward "were important, if not always successful or well-intentioned, participants in Stax's moment of greatest political engagement and national popularity"(97). Hughes suggests that the disruption felt by Cropper and Axton might have been the consequence of shifting power relations. The acclaimed "racial utopia" at Stax had never really existed. Baylor's and Woodward's sometimes strong-arm efforts to support black workers (including musicians) at least in part addressed the earlier inequalities that had characterized life at Stax. He supports that suggestion through a careful reading of published and unpublished sources, including interviews with black session musicians as well as more frequently cited sources such as a biography of Ahmet Ertegun.

In fact, one of the hallmarks of this book is Hughes's ability to support his claims through deep research in archives, in-depth interviews with key players, and an immersion in the relevant published literature. This is further evidence of the maturation of popular music studies. Hughes dug deeply into the expanding archives of popular music, including the Portia Maultsby Collection at Indiana University, the Southern Folklife Collection and the Jerry Wexler Collection at the University of North Carolina, the Rock and Roll Hall of Fame and Museum 
Library and Archives, including the Spooner Oldham Papers and Jerry Wexler Papers, the Memphis public library and the University of Memphis Libraries, the National Museum of American history and the Rock and Soul Video History Project, and Memphis Rock 'n' Soul Exhibit Archives. Interviews with major players, some of them originally conducted by Richard Younger, but most completed by Hughes himself, reveal subtle nuances of the complexities of interpersonal relationships among musicians and music industry professionals that ears and eyes attuned to the lower frequencies could pick up. The shift in perspective changes the framework through which the story can be told. Consequently, the story changes.

Hughes exploits recently developed archives in the service of revised histories; Kajikawa develops new analytical concepts that become the foundation for methodological innovations. In Top 40 Democracy, Eric Weisbard performs some of both. Most significantly, Weisbard wants to overturn popular music studies' long entanglement with problems of genre, replacing it with a focus on formats. In the foundational work of such as scholars as Simon Frith and Fabian Holt, the concept of genre enabled many of the key moves in the analysis of popular music. ${ }^{5}$ Genres tie together musical codes and social identities and, therefore, provide a key means to thinking about popular music's social and political impact. Weisbard doesn't exactly want to do away with all that. But he does argue that this approach reinforces a certain essentialism. Building on Karl Hagstrom Miller's discussion of the difference between performative authenticity and folkloric authenticity, Weisbard links the concept of genre to the 1920's folkloric assumption that the proper use of musical conventions must necessarily rest on the public identities of the musicians. ${ }^{6}$ This assumption generates numerous difficulties since the history of American popular music is one of cultural mixing and boundary crossing. As Weisbard describes it, genre becomes a tool used in the drive for purity, and he is right to reject this understanding of the concept. In its place, he wants us to pay attention to format.

Near the very beginning of this book, Weisbard boldly states, "The objective of formats was to garner ads and sell records, but a flow of songs and banter had to be shaped and polished, an audience had to be defined. Formats did not just sell music - they normalized it. Formats did not just sell products-they touted categories of consumers" (2). For Weisbard, the concept of format offers a number of advantages. Formats are messy. They are fundamentally linked to the commercial operations of the music industry. Paying attention to formats inverts the standard power hierarchies of popular music studies insofar as it shifts our attention away from the restricted field of popular music production, where musicians compete for the esteem and acclaim of other musicians, and towards the general field, which is affected much more directly by external forces. Formats are used by radio stations and, to a lesser extent, by record companies to attract listeners and consumers. In general, although not absolutely, formats do not discriminate among their listeners. In particular, actors in the music industry whose efforts are structured by format-thinking care little about whether or not 
their listeners display critical attention to their listening habits. In Weisbard's analysis, formats are the servants of the ordinary, the common, the demos at its most capacious - defined as normal consumers.

The primary format with which Weisbard is concerned is Top 40, although he spends time with Adult Contemporary (A/C), Album Oriented Radio (AOR), and Country. Purposefully centering his analyses on artists and industry personnel who tilled the center of these formats, Weisbard wants us to understand and value the creativity and sheer ambition of these individuals. He also wants us to stop dismissing the taste of mainstream radio listeners and record buyers. The fans of the Isley Brothers, Dolly Parton, the Carpenters, Elton John, Bob Seger, and others like them lie at the imagined center of Weisbard's revisionism. For those listeners, the musicians they listened to, and the industry personnel who strove to bring them together, "Top 40 brandished aspirational modernity. Chart climbing equated with social mobility" (157). Weisbard celebrates and champions the music industry's construction of the normal and the channeling of the energies produced by the desire for social mobility within the confines of the normal.

For most of its existence, popular music studies has sought to legitimate itself by critiquing the industry's construction of the normal. The historical and analytical focus has been on outsiders, on those excluded from the middle. This tendency so structures the field that discussions of the Beatles or Elvis Presley or other such indisputably central figures have to be legitimated by rooting analyses of their work in their outsider origins. ${ }^{7}$ The value of these canonical figures has been aligned with their critique of the normal, their demand, often obliquely stated but audible nevertheless, that the curve of the normal be shifted to accommodate them. In Top 40 Democracy, Weisbard attempts something quite different from this standard approach. He focuses not on the desire to change what counts as normal but the sheer anxious hunger to be included within it. In this version of the story, The Isley Brothers, Dolly Parton, Elton John, and the Carpenters share with Jerry Moss, Herb Alpert (founders of A\&M records) and John Gorman (program director for one of Cleveland's AOR stations, WMMS) the belief that the American dream of a vibrant normal center can be an inclusive one. As Weisbard puts it, "Top 40 stations, despite subdivisions, remained the most likely to target racially mixed and working-class listeners and challenge niche capitalism with novel inclusiveness" (191). It championed the recognition of outsiders as insiders. A cynical critic might say, "well yes, outsiders were allowed in so long as they could modify themselves to fit the narrow confines of that normal." The American center could be racially inclusive so long as you did not directly challenge white supremacy. Black radio stations that began with a Black Power message found they had to drop their politics in order to remain financially viable. Top 40's normal could appeal to the working class so long as listeners aped and aspired to the norms of middle-class striving. WMMS could not maintain its focus on the rowdiness of white working-class males because of their lack of evident spending power. Like Dolly Parton, you could be a strong independent woman in country music so long as you successfully performed 


\section{Barry Shank}

the traditional signs of femininity. All you had to do to belong to the Top 40 democracy was sign on to this normalizing project.

But the truly curious aspect to the story that Weisbard tells is that the Isley Brothers, Dolly Parton, Elton John, and the Carpenters did change the shape of the normal. They achieved this transformation through their efforts to perform the normal. As Judith Butler taught us all decades ago, every iteration of the norm is necessarily incomplete. ${ }^{8}$ Every effort at replication fails and, therefore, creates something new. The Isley Brothers established the normality of the African American middle-class suburban family as part of the central American narrative. Dolly Parton established the normality of the fiercely and overtly ambitious independent female country singer. Elton John exposed the normality of flamboyant queerness at the heart of the pop process, while remaining closeted for so much of his career. The Carpenters' desire to perform domestic tranquility exposed the painful gaping emptiness at the heart of it. Homemakers and office workers who listened to Adult Contemporary while performing their duties became the prized targets of format-shaping executives. Weisbard's point here, I believe, is to render evident the complexity and internal differentiation of the American normal, the twisted yet productive creative force that emerges from the longing to belong.

Much like Charles Hughes did, Weisbard grounds his claims in the burgeoning archives of popular music studies. Consulting sources at Bowling Green University's recorded sound archives, the Rock and Roll Hall of Fame Library and Archives, The Country Music Hall of Fame, the New York Public Library, the Schomburg Center for Research in Black Culture, the University of Maryland's Library of American Broadcasting, along with the personal files of and interviews with Jerry Moss and Herb Albert, John Gorman and numerous other individuals who worked at WMMS, Weisbard has cultivated his delicate revision of our standard understanding of mainstream popular music from very rich soil. These sources do not contain evidence of ideological or musical purity but revel in the mixed motives of and muddled influences on individuals trying to make a living in the messy puddle of contradiction that is American life. They do not offer easy lessons or clearly evident guides to proper behavior. Instead they illustrate the frustrations and satisfactions that come from the interplay of gain and loss in a world structured by the inequalities and injustices of history.

This sensitivity to contradiction, and the desire to respect but not bury it, is what the best of current popular music studies can offer to active scholars in American studies. Kajikawa, Hughes, and Weisbard have each opened new directions in the analysis of popular music that treat the sounds and the testimonies of producers, musicians, listeners, homemakers, office workers, and others as evidence of the real struggles in which they were thrown and out of which their lives emerged. Al Bell, Hank Schocklee, Karen Carpenter, Dolly Parton, Porter Wagoner, Charley Pride, Dan Penn, Dr. Dre, Herb Alpert, John Gorman, and the rest of the individuals who created the work covered in these three excellent books - each operated in a world unequally and violently structured by race, 
class, gender, sexuality, and the rest of the divisions in American society. None of them had it all figured out. Each of them made the best of it they could. Some were less interested in changing those structures and conditions than others were. Each of them took actions that we should critique. Where they all met was in the effort to create music that was meaningful and pleasurable enough to a broad enough swath of listeners that those listeners would spend whatever spare money they had to get more of it while the creators could continue to do their work in the commercialized world of popular music. The three scholars who have chronicled and analyzed their efforts have made it possible for us to understand more clearly and more thoroughly the difficulties of that task and the immensity of the challenges they faced.

In 1990, George Lipsitz asked scholars of American studies to begin "Listening to Learn" and "Learning to Listen." He closed that important essay by reminding us that the sounds that matter "cannot be summoned up by theoretical expertise alone. They cannot be constructed out of idealized subject positions emanating from reforms in discursive practice. They are to be found in the concrete contests of everyday life." As the books under review show us, there is still more to learn from the popular music ordinary Americans listen to. Musicians who strive to reach large audiences produce grey-scale auditory images of the world around them. People who would otherwise never talk to each other find common pleasure in sounds that subtly transform the common sense of the normal. The war of position that maps the political consequences of culture is not a linear one. It moves by fits and starts, sideways steps, and steep climbs. Progress towards social justice is supported and promoted by the spread of shared understanding and feeling. It is also supported and promoted by the harsh insistence on specific truths that have been ignored for decades or centuries. Democracy is a muddle. And the lessons of history change. The outsider's story is the normal story in America. It is the story we love to tell ourselves. It is one thing we all claim to have in common. Like any cliché, the centrality of the outsider is easy to dismiss. It is what enables career politicians to run against government. But like all clichés, it captures something important. The outsider who becomes an insider changes the shared understanding of the normal. The ceaseless struggle for the normal is part of the power that has moved rap to the center of American and global musical culture. The ceaseless struggle for the normal is part of what stimulated southern musicians to create masterpieces of country and soul music. The ceaseless struggle for the normal now generates a popular musical culture where Taylor Swift's display of corporate control, 1989, provides a model for female CEOs, and a popular musical culture where Kendrick Lamar's masterpiece of political critique and social anxiety, To Pimp a Butterfly, is not only acclaimed by critics and adored by fans, but also receives eleven Grammy nominations. There is action in the center. We should not ignore it. 


\section{Barry Shank}

\section{Notes}

1. Tricia Rose, Black Noise: Rap Music and Black Culture in Contemporary America (Middleton, CT: Wesleyan University Press, 1994); Murray Forman and Mark Anthony Neal, eds., That's the Joint: The Hip-Hop Studies Reader, $2^{\text {nd }}$ ed, (New York, NY: Routledge, 2011); Imani Perry, Prophets of the Hood: Poetics and Politics in Hip Hop (Durham, N.C.: Duke University Press, 2004); Cheryl Keyes, Rap Music and Street Consciousness (Urbana-Champaign, IL: University of Illinois Press, 2004); Mark Katz, Groove Music: The Art and Culture of the Hip-Hop DJ (New York, NY: Oxford University Press, 2012); Joe Schloss, Making Beats: The Art of Sample-Based Hip-Hop, $2^{\text {nd }}$ ed. (Middleton, CT: Wesleyan University Press, 2014).

2. Robert Walser, "Rhythm, Rhyme, and Rhetoric in the Music of Public Enemy," Ethnomusicology 39, no. 2 (1995): 193-217.

3. Nelson George, The Death of Rhythm and Blues, (1988; reis., New York, NY: Penguin Books, 2003); Craig Werner, A Change is Gonna Come: Music, Race, and the Soul of America, Revised Edition (Ann Arbor: University of Michigan Press, 2006); Brian Ward, Just My Soul Responding: Rhythm and Blues, Black Consciousness, and Race Relations (Berkeley, CA: University of California Press, 1998).

4. See for example, Reebee Garafalo, Rockin'Out: Popular Music in the U.S.A, $4^{\text {th }}$ ed. (Upper Saddle River, NJ: Pearson/Prentice Hall, 2008); Elizabeth F. Barkley, Crossroads: The Multicultural Roots of America's Popular Music, $2^{\text {nd }}$ ed. (Upper Saddle River, NJ: Pearson/Prentice Hall, 2007).

5. Simon Frith, Performing Rites: On the Value of Popular Music (Cambridge, MA: Harvard University Press, 1996); Fabian Holt, Genre/in/Popular/Music (Chicago, IL: University of Chicago Press, 2007).

6. Karl Hagstrom Miller, Segregating Sound: Inventing Folk and Pop Music in the Age of Jim Crow (Durham, N.C.: Duke University Press, 2010).

7. See Mark Lewisohn, Tune In, The Beatles: All These Years, Vol. 1 (New York, NY: Crown Archetype, 2013); Peter Guralnick, Last Train to Memphis: The Rise of Elvis Presley (Boston, MA: Bay Books, 1995).

8. Judith Butler, Gender Trouble: Feminism and the Subversion of Identity (New York, NY: Routledge, 1990).

9. George Lipsitz, "Listening to Learn and Learning to Listen: Popular Culture, Cultural Theory, and American Studies," American Quarterly 42, no.4 (December, 1990): 615-36, 633. 